REVISTA CHILENA DE LITERATURA

Noviembre 2009, Número 75, 325 - 329

\title{
ENTREVISTA A FÉLIX MARTÍNEZ BONATI
}

\author{
Por Cristián Montes*
}

Félix Martínez Bonati (1929) es considerado uno de los teóricos de la literatura más importante del mundo hispánico. Actualmente es Profesor Emérito de la Columbia University de Nueva York. Es autor de numerosos ensayos y libros, donde destaca $L a$ estructura de la obra literaria (Santiago: Universidad de Chile, 1962; otras ediciones: Barcelona: Seix Barral, 1974; Madrid: Ariel, 1988). La versión inglesa, ampliada, de este libro, se publicó con el título de "Fictive Discours" (Ithaca:Cornell University Press, 1982). Otro de sus libros fundamentales es El Quijote y la poética de la Novela (Alcalá de Henares: Centro de Estudios Cervantinos, 1955. Este libro fué traducido al inglés: Don Quixote and the Poetics of the Nove; Ithaca, Cornell University Press, 1992). Cabe destacar, igualmente, el libro La ficción narrativa. Su lógica y ontología (Murcia: Universidad de Murcia, 1992; 2.a ed. Santiago: LOM Ediciones, 2001). En septiembre de 2003 fue publicado en Chile un libro en su homenaje.

C.M. Comparando la situación académica de los años cincuenta-fecha en que Ud. inició en Chile sus estudios universitarios-y la de ahora, ¿qué cambios y transformaciones ha podido apreciar?

F.M. El panorama intelectual de las Humanidades en Chile (me limito a esas disciplinas) a mediados del siglo veinte era relativamente estrecho. Las corrientes internacionales fluían principalmente en traducciones españolas. Se leía poco en inglés o alemán, algo en francés. Rodolfo Oroz nos hacía ver, sin sermonearnos, que eso era insuficiente, y siempre nos presentaba largas bibliografías en varias lenguas al iniciar sus cursos. En las publicaciones chilenas de hoy, el campo de referencia es amplísimo, no diferente del que tienen las europeas o norteamericanas, más amplio a veces que estas últimas, ya que allí el dialogo intranacional es muy denso y, aunque bien llevado, tiende a limitar la visión. La apertura de los norteamericanos al pensamiento europeo continental (a lo que se hace en Inglaterra estuvieron siempre atentos) es relativamente reciente. En los estudios literarios

* Académico del Departamento de Literatura de la Facultad de Filosofía y Humanidades de la Universidad de Chile. Doctor en Literatura. Los temas de sus publicaciones son la narrativa chilena y la literatura latinoamericana. 
se debió en buena medida a la influencia de europeos avecindados como Wellek, Jakobson o Paul De Man. En la filosofía, a Derrida o Ricoeur. Nosotros leíamos las traducciones españolas de Husserl y de Heidegger (para dar un ejemplo) cuarenta años antes de que se hicieran tales traducciones al inglés. Y no es que los filósofos norteamericanos lean ordinariamente alemán. A la inversa, nuestra recepción del pensamiento anglosajón ha sido tardía y solo ahora puede decirse que nos nutre regularmente. Claro que para todo hay excepciones: hace mucho que Ibáñez Langlois incorporó el New Criticism a su pensamiento teórico, y Cedomil Goic a diversos tratadistas norteamericanos de la novela al suyo. Creo que estamos hoy, en lo que respecta a la información de la producción internacional contemporánea, a la altura de los tiempos.

Verdad es que la amplitud de nuestra recepción de tantas influencias y la falta de una tradición propia fuerte, da lugar a cierta fragmentación y dispersión de nuestro estudio en las Humanidades. El problema ahora es talvez dar continuidad a las líneas de investigación y abrir más el diálogo entre las escuelas, separadas por sus variadas orientaciones. De todas maneras hay que reconocer lo bien informada que está la intelectualidad chilena, pese a las dificultades de acceso a la bibliografía que sigue habiendo en el país, compensadas, eso sí, por una facilidad de viajar a las metrópolis, impensable cincuenta años atrás. En estos días he estado leyendo obras recientes de Grínor Rojo, Jorge Peña Vial y Gonzalo Portales. Me parece que su posesión del "state of the art" de sus respectivos campos de trabajo no puede ser mejor.

C.M. ¿Puede decirnos algo de la diferencia entre los Estados Unidos y Chile, respecto a la formación universitaria ofrecida a los estudiantes de literatura?

F.M. En Chile, como en otros países de orientación semejante, se intenta dar a los estudiantes desde la partida una formación básica general, sistemática y completa, que abarca todos los periodos de la historia literaria, las disciplinas lingüísticas fundamentales, la historia de las ideas, una introducción a la filosofía, y otros cursos. Y se proyecta que el estudiante haga hacia el final de sus estudios un trabajo de genuina investigación, especializada, delimitada. En los Estados Unidos, se empieza por pedir a los estudiantes investigaciones, modestas, pero originales, y en la mayor parte de sus estudios tienen que hacer concretos proyectos de búsqueda innovativa. El estudiante allí se doctora produciendo un aporte novedoso en un campo generalmente mínimo (como corresponde al destino y estado de la disciplina hoy) y egresa con enormes vacíos de información sistemática e histórica. En la profesión docente, en colleges y universidades, se ve obligado a enseñar, sobre todo en cursos de pregrado, materias varias y ajenas a la especialidad estricta de su doctorado. Así va adquiriendo la formación general que no se le da como estudiante.

He exagerado un poco esta oposición educativa, pero hay verdad en ella, pues el proceso de formación es en buena medida inverso aquí y allá. Podríamos decir que el valor que predomina en los estudios humanísticos norteamericanos es la investigación, la Ciencia (en cierto sentido) y la creatividad individual, y entre nosotros, la cultura o el patrimonio tradicional. En la práctica, hay siempre mezclas de ambos tipos ideales. Pero la realidad, el tiempo disponible, impide una fusión de ambos y nos fuerza a sacrificios intelectuales de uno u otro orden. Las presiones institucionales y públicas 
para acortar la duración de los estudios de doctorado - las hay en todas partes porque es hoy normal que un estudiante de las Humanidades finalice sus estudios de doctorado alrededor de sus treinta años, más bien después que antes- tienden a estrechar más aún la especialización.

En las disciplinas humanísticas esto tiene seria consecuencias, porque, a diferencia de las ciencias "duras", en que se puede ingresar al estado actual de la investigación sin rehacer el camino secular que ha llevado allí, en las Humanidades hay que rehacer la historia de la disciplina si se quiere llegar a fondo en la investigación. Un estudiante de las ciencias naturales no tiene que ocuparse de los textos pertinentes de Aristóteles; un estudiante de letras tiene que estudiar muy bien la poética y se verá constantemente remitido a ella. El modelo científico duro del conocimiento no puede aplicarse a los estudios humanísticos sino limitadamente. Ha habido reciente esfuerzos (en Alemania y otras partes) por desarrollar los estudios literarios como ciencia empírica positiva, pero aunque han de dar resultados útiles, nunca podrán desplazar a la tarea tradicional de las Humanidades, que es la toma de conciencia que hacemos de nuestra historia y de nuestra constitución espiritual profunda.

Por esta tarea estamos expuestos a deformaciones idiosincrásicas e ideológicas del conocimiento, pero no condenados a ellas, $\mathrm{y}$, por otra parte, la fundamental búsqueda de claridad y objetividad no nos obliga a un positivismo ciego para las grandes preguntas.

C.M. Ud. se ha ocupado siempre tanto de los estudios filosóficos como de los literarios. ¿Qué lo ha impulsado en esta doble dirección?

F.M. Por una parte, ha sido mi inclinación personal el unir ambas disciplinas a través de preguntas que tienen por materia la experiencia literaria, pero son de orden general, apuntan a sus rasgos universales y, por eso, más que indagación de hechos nuevos, requieren reflexión sobre los ya vividos. Dicho en pocas palabras: se trata de interrogantes teóricas. A partir de ellas he ido pasando a temas históricos y concretos, sin que pueda trazar una línea rigurosa de separación entre la filosofía y la filología (en sentido amplio). La historia de los estudios literarios, desde la Antigüedad, muestra su íntima relación con las concepciones filosóficas: platónicas, aristotélicas, romántico-idealista, historicistas, fenomenológicas, neomarxistas, desconstructivistas, etc.

Diría que en la actualidad se ha acentuado la dimensión teórica de los estudios literarios, en parte por razones de su ideologización y desideologización, en parte por la necesidad de crear nuevas líneas productivas de investigación. Pero (siempre insisto en ello) debe tenerse presente que una parte fundamental, en rigor: la fundamental, de los estudios literarios, la que da la base para todo lo demás, es la filología en el sentido más estricto: la determinación exacta de todos los textos y de sus códigos pertinentes, sin lo cual no habría interpretación de interés ni experiencia literaria superior. Se hacen cientos de estudios sobre El Quijote, por ejemplo, muchos altamente especulativos, pero creo que ninguno de los recientes es tan valioso como la simple (y complejísima) edición que entregó Francisco Rico hace pocos años. Operan en este trabajo las mejores tradiciones de la filología, pero nada de filosofías elaboradas o metodologías a la moda. Las obras literarias solo pueden escribirse en lenguas y lenguajes alusivos históricamente 
circunscritos, y la observación y recuperación de los códigos pertinentes es el sine qua non de todo estudio serio. Pienso que se hace poco en este sentido en los estudios literarios nuestros. Ediciones anotadas inclusive de autores contemporáneos servirán para salvar tesoros de alusiones recónditas, giros perecederos, implicaciones compartidas, pero momentáneas, etc.

\section{C.M. ¿Cuál cree Ud. que ha sido su propia contribución a los estudios literarios?}

F.M. Comencé con un proyecto filosófico, la descripción de la estructura esencial del discurso literario, la estructura de la obra literaria. Se trataba de una investigación de máxima generalidad y por eso sus resultados fueron descripciones (inspiradas por el método fenomenológico) de formas transhistóricas o ahistóricas de la literatura. Ocurrió que al acentuar así la cohesión interna de las obras literarias, su riguroso esqueleto básico, contribuí a que mis colegas de mi misma generación y algunos de nuestros alumnos se adentraran en la exploración de formas literarias, así genéricas como singulares, y destacaran en sus estudios el universo ficticio de la obra como centro de nuestra experiencia literaria. Coincidió históricamente este trabajo mío (escrito hacia fines de los años cincuenta y publicado en 1960) con la emergencia y difusión, en los años sesenta, del estructuralismo en los estudios literarios (Genette, Todorov, Barthes, etc.) y con el desarrollo de la narratología contemporánea. Yo no me había inspirado en el estructuralismo, que conocía en la lingüística, sino en el concepto de estructura (muy diferente) de la fenómenologia husseerliana. Pero estas aproximaciones comparten supuestos básicos y son convergentes.

Con el tiempo he ido pasando del estudio de formas intemporales al de formas definidamente históricas, en especial, de la evolución de la novela. En mi libro sobre el Quijote y en algunos ensayos posteriores he tratado de interpretar las transformaciones del género en relación con las transformaciones del espíritu moderno, desde el renacimiento y en particular desde el siglo dieciocho. Mi hipótesis general de trabajo es que el significado (el sentido y valor) de las obras literarias, manifiesto intuitivamente en la lectura adecuada, se puede parcialmente conceptualizar gracias al estudio de la forma artística. La forma es el modo que tiene la obra de articular la presencia del mundo. Estos modos de la representación ficcional de la vida son en parte intemporales, pero en su parte distintiva, en la que se constituyen como estilos de visión, son respuestas a las situaciones históricas del espíritu humano. Trato de determinar los procesos del espíritu moderno que operan bajo las mutaciones formales del género novelístico.

Mi método es, pues, una actualización de la llamada historia del espíritu (Geistesgeschichte) a través de la poética, en especial de la investigación narratológica. Ello lleva a desembocar más allá de la literatura, en los temas centrales de nuestra comunidad cultural. Me ocupa eminentemente lo que llamo el pensamiento romántico, una corriente viva desde el romanticismo en sentido histórico estricto, de alrededor de 1800 , hasta nuestros días y que, por razones que requieren mayor espacio para su explicación, tendrá necesariamente que proseguir en el futuro. Me esfuerzo por comprender las formas que este pensamiento toma en la filosofía y en las artes, en especial, como dije, en la literatura narrativa. De eso tratan los ensayos que quiero reunir ahora en un libro: $L a$ agonía del pensamiento romántico: cuatro ensayos sobre nuestra situación intelectual. 
C.M. Ud. reside fuera de Chile la mayor parte del año, pero viene regularmente a dar algunos cursos. ¿Cuál es su relación con su país natal?

F.M. Sabemos que el país en que uno crece y se forma, el mundo de la niñez y juventud, está en la médula de la substancia personal. Fuera de él se vive a pedazos. Volver al país permite recuperar algo de la hondura y vertebración del ser propio, a la vez que poder contribuir a los trabajos comunes. Sin poder reincorpórame por completo, trato de hacerlo en espíritu, leyendo y viendo todo lo que puedo de la expresión nacional, que todavía me parece inabarcablemente rica. Deberíamos hacer, en equipo, una suerte de mapa de las corrientes intelectuales del Chile actual, un inventario orientador de ideas, formas y tendencias. Creo que mostraría un universo espiritual significativo, de un alcance mayor.

Enero de 2009 